\title{
Co-Expression of Putative Pheromone Receptors in the Sensory Neurons of the Vomeronasal Organ
}

\author{
Sara Martini, ${ }^{1}$ Lucia Silvotti, ${ }^{1}$ Arild Shirazi, ${ }^{2}$ Nicholas J. P. Ryba, ${ }^{2}$ and Roberto Tirindelli ${ }^{1}$ \\ 1/stituto di Fisiologia Umana, Universita' di Parma, I-43100 Parma, Italy and ${ }^{2 N a t i o n a l ~ I n s t i t u t e ~ o f ~ D e n t a l ~ a n d ~ C r a n i o f a c i a l ~}$ \\ Research, National Institutes of Health, Bethesda, Maryland 20892
}

Two large and divergent families of G-protein-coupled receptors (V1Rs and V2Rs) are expressed in subsets of neurons in the vomeronasal organ. These receptors are likely to mediate pheromone responses, but it appears that many V2R genes may encode expressed pseudogenes rather than functional proteins. Therefore we have raised antibodies to representative V2Rs and show labeling of vomeronasal neurons demonstrating that V2R genes encode expressed receptors. V2R immunoreactivity was detected at the sensory surface of the vomeronasal organ in dendritic terminals, indicating that these receptors are capable of directly interacting with pheromones and mediating physiological responses. Immunohistochemistry confirmed that three V2R receptors are expressed in small subsets of sensory neurons. However, surprisingly we found that a subfamily of V2R genes is broadly expressed in the Go $\alpha$-layer of the vomeronasal organ and are coexpressed in the same cells as other V2Rs. This is in direct contrast to the main olfactory epithelium where sensory neurons express only a single receptor. Thus, our results suggest that different modes of the information processing may occur in the main and accessory olfactory systems.

Key words: vomeronasal organ; pheromone receptors; G-protein-coupled receptors; immunohistochemistry; coexpression; olfaction; pheromone; receptors and signal transduction; chemosensory receptors; sensory coding
Mammalian pheromones are thought to be diverse chemical signals that play a role in controlling interactions between individuals of a single species (Keverne, 1983; Novotny et al., 1986; Halpern, 1987; Tirindelli et al., 1998). For example, under specific conditions, pheromones evoke neuroendocrine responses among conspecifics resulting in mating (Keverne, 1983). Thus subtle changes in response to pheromones may provide an important mode of speciation.

The vomeronasal organ (VNO) is a chemosensory organ located at the base of the nasal septum of most terrestrial vertebrates that plays a major role in pheromone responses in many mammalian species (Halpern, 1987). Molecular analysis of VNO neurons has revealed unexpected functional differences between this organ and the main olfactory epithelium (Berghard et al., 1996; Wu et al., 1996). In the VNO, the G-proteins $\mathrm{G} \alpha_{\mathrm{i} 2}$ and $\mathrm{G} \alpha_{\mathrm{o}}$ are expressed in distinct subsets of mature sensory neurons (Halpern et al., 1995; Berghard and Buck, 1996; Jia and Halpern, 1996). Two large and unrelated families of G-protein-coupled receptors, the V1Rs and V2Rs, are expressed in small subsets of the neurons containing $\mathrm{G} \alpha \mathrm{i}_{2}$ and $\mathrm{G} \alpha{ }_{\mathrm{o}}$, respectively, and may encode pheromone receptors (Dulac and Axel, 1995; Herrada and Dulac, 1997; Matsunami and Buck, 1997; Ryba and Tirindelli, 1997). It has been demonstrated that a V1R (VN6) is found in the sensory microvilli, supporting this idea (Takigami et al., 1999). Moreover, the pattern of cellular activation of VNO neurons in response to pheromones parallels the expression pattern

Received Sept. 6, 2000; revised Nov. 6, 2000; accepted Nov. 10, 2000

This research was supported by the Italian Ministero dell'Universita' e della Ricerca Scientifica e Tecnologica. New sequences of V2R2-subfamily members have been deposited in GenBank with accession numbers AF318939 and AF318940. We thank Dr. R. Percudani for helpful discussion.

Correspondence should be addressed to Roberto Tirindelli, Istituto di Fisiologia Umana, Via Volturno, 39, I-43100, Parma, Italy. E-mail: robertin@unipr.it.

Copyright (C) 2001 Society for Neuroscience $0270-6474 / 01 / 210843-06 \$ 15.00 / 0$ of receptors (Holy et al., 2000; Leinders-Zufall et al., 2000). However, there is no direct evidence that any of these molecules are pheromone receptors.

The V2Rs are homologous to the extracellular Ca-sensing receptors (Brown et al., 1993), metabotropic glutamate receptors (Nakanishi, 1992), taste receptors (Hoon et al., 1999), and a family of fish receptors that also appear to play chemosensory role (Cao et al., 1998; Naito et al., 1998; Speca et al., 1999). All these receptors possess a large N-terminal extracellular domain that is likely to form the ligand-binding site (Nakanishi, 1992; Brown et al., 1993). The ligand specificity of one of these receptors (receptor 5.24) from goldfish olfactory epithelium was recently reported (Speca et al., 1999). This receptor is activated primarily by the basic amino acids, arginine and lysine, which are odorants for the fish. One intriguing facet of the expression of receptor 5.24 is that it is widely expressed in the olfactory epithelium. In contrast, many other receptors are expressed in small subsets of cells (Cao et al., 1998; Naito et al., 1998; Speca et al., 1999).

We raised antibodies to several V2Rs to examine expression of these proteins and to investigate their cellular distribution. Immunohistochemistry demonstrates that V2R genes encode proteins that are expressed in the VNO and are likely to function as pheromone receptors. Surprisingly, we observed that V2R2 is expressed at a lower level in almost all the VNO neurons of the $\mathrm{G} \alpha \mathrm{O}$-positive layer, suggesting that cellular responses to pheromones may involve the interaction between receptors of the same family.

\section{MATERIALS AND METHODS}

Isolation and expression of the $V N O$ receptors. Escherichia coli expression systems were used to produce peptides encoding part of the extracellular domain of V2Rs. A fragment of the mouse receptor, V2R2 (bases 1053-1807), was subcloned in pET28 (Novagen, Madison, WI). The equivalent region of the extracellular domains of other V2Rs: mouse 
Figure 1. Cellular distribution of the V2Rs. Representative rat V2Rs: Go-VN2 (a), Go-VN3 (b), and Go-VN4 (c) were studied by immunohistochemistry in coronal sections of rat VNO; strong staining of a small subset of VNO neurons was observed; dotted lines indicate the basal and luminal edge of the sensory epithelium. The number of antibody staining cells was quantitated and compared with in situ hybridization of corresponding V2R probes by counting positive cells in double-labeled sections. Similar numbers of cells were detected with antibodies and riboprobes for Go-VN2 and Go-VN3, but antibodies to Go-VN4 detected 4172 cells in 40 sections (4 rats), whereas only 1560 cells were positive by in situ hybridization. High magnification of the luminal region of the VNO stained with the anti-VN4 antibody $(d)$ highlights labeling of sensory dendrites and knobs; arrows indicate immunopositive knobs and dendrites on the surface of the VNO epithelium. Scale bars: $a-c, 100 \mu \mathrm{m}$; $d, 25 \mu \mathrm{m}$.
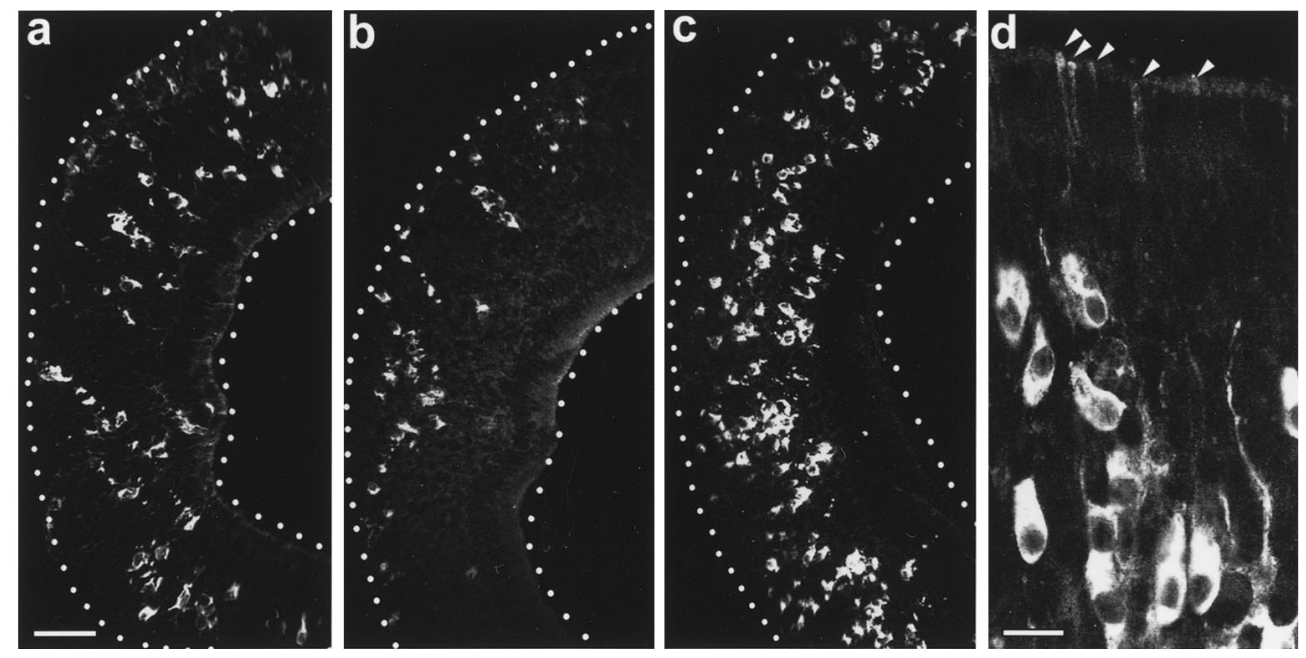

V2R1 (991-1669), rat Go-VN1 (986-1738), rat Go-VN2 (975-1730), rat Go-VN3 (1577-2332) and rat Go-VN4 (1110-1868) (Herrada and Dulac, 1997; Ryba and Tirindelli, 1997), were amplified from cDNA, sequenced and subcloned in the plasmid pTrcHis2 (Invitrogen, San Diego, CA). The untranslated region of three distinct members of the V2R2 subfamily were amplified and subcloned in pCRII. A fragment encoding the rat homolog of the human receptor related to goldfish receptor 5.24 was generated by degenerate PCR of genomic DNA using primers preceding the first and sixth transmembrane helices. Peptide expression was induced with isopropylthiogalactoside according to standard methods (Invitrogen; Novagen). Bacterial pellets were resuspended in $10 \mathrm{~mm}$ Tris, $150 \mathrm{~mm} \mathrm{NaCl}$, and $1 \mathrm{~mm}$ PMSF and sonicated for $1 \mathrm{~min}$. After centrifugation, pellets were dissolved in $6 \mathrm{~m}$ guanidinum- $\mathrm{HCl}$ in resuspension buffer. Purification of the peptide was performed by affinity chromatography onto a Talon metal affinity resin (Clontech, Palo Alto, CA) according to the manufacturer's instruction. Approximately 2-4 mg was obtained from $200 \mathrm{ml}$ culture.

For Southern hybridization, a fragment of mouse V2R2 corresponding to a single extracellular exon (540-1388) and the $3^{\prime}$ nontranslated region of rat V2R2, V2R2a, and V2R2b were amplified by PCR. Southern blots were washed at high stringency $\left(1 \mathrm{hr}\right.$ at $65^{\circ} \mathrm{C}$ in $0.1 \times \mathrm{SSC}$ for the extracellular probe and $20 \mathrm{~min}$ at $65^{\circ} \mathrm{C}$ in $0.5 \times \mathrm{SSC}$ for the $3^{\prime}$ nontranslated region probes). The rat cDNA library was screened at moderate stringency with a probe to V2R2 (filters were washed at $65^{\circ} \mathrm{C}$ in $1 \times \mathrm{SSC}$ ).

Antibody generation and Western blotting. The V2R extracellular domain fragments were extensively dialyzed against PBS, and the precipitate that formed was used to immunize rabbits (500-1000 $\mu \mathrm{g}$ each injection). Antibody purification was performed by ammonium sulfate precipitation followed by DEAE exclusion chromatography (Harlow and Lane, 1988). Because the fusion proteins all contained hexahistidine tags, antibodies were preabsorped with a saturated solution of polyhistidine to reduce cross-reactivity. Antibodies were used at a concentration of $20 \mathrm{ng} / \mathrm{ml}$ for Go-VN2, $45 \mathrm{ng} / \mathrm{ml}$ for Go-VN3, $4 \mathrm{ng} / \mathrm{ml}$ for Go-VN4, and $1-20 \mathrm{ng} / \mathrm{ml}$ for V2R2. Antibodies were assayed by Western blot analysis of crude plasma membrane preparation from rat $\mathrm{VNO}$ and control tissues (Tirindelli and Ryba, 1996).

In situ hybridization and immunohistochemistry. Tissue was obtained from adult Wistar rats and C57BL/6 mice. Frozen sections were cut at 14 $\mu \mathrm{m}$ and attached to silanized slides. Probe preparation and in situ procedures were essentially as described previously (Ryba and Tirindelli, 1997). Riboprobes were labeled with digoxigenin, and signal was developed using an alkaline phosphatase-conjugated antibody and chromogenic substrate. For double-label fluorescent detection, probes were labeled with fluorescein or with digoxigenin. An alkaline-phosphataseconjugated anti-fluorescein antibody (Amersham Pharmacia Biotech, UK) and a horseradish-peroxidase conjugated anti-digoxigenin antibody were used in combination with fast red and tyramide fluorogenic substrates (Boehringer Mannheim, Indianapolis, IN; New England Nuclear, Boston, MA). Confocal images were obtained with a Leica (Nussloch,
Germany) TSC confocal microscope using an argon-krypton laser; $1 \mu \mathrm{m}$ optical sections were recorded to ensure that any overlapping signal originated from single cells.

For immunohistochemistry, sections were prepared as for the in situ hybridization, blocked in $1 \%$ albumin and $0.3 \%$ Triton X-100 (blocking solution) for $20 \mathrm{~min}$ and incubated with the anti-V2R2 antibody in blocking solution. For double-label immunohistochemistry, anti-V2R2 antibody was labeled with $N$-hydroxysuccinimide biotin (Sigma, St. Louis, MO) at a ratio of 5:1. Sections were first incubated with the anti-VN antibody and developed with an anti-rabbit IgG conjugated with Alexa-586. After blocking with normal rabbit serum, sections were incubated with $20 \mathrm{ng} / \mathrm{ml}$ biotinylated anti-V2R2 antibody (Harlow and Lane, 1988 ) in presence of $10 \%$ normal rabbit serum, and immune complexes were visualized with fluorescein avidin (Vector Laboratories, Burlingame, CA). For preabsoption controls, $5 \mu \mathrm{g}$ of anti-V2R2 antibody was incubated with $10 \mu \mathrm{g}$ of the polypeptide against which it was raised or a mix of $10 \mu \mathrm{g}$ of each of the other V2R polypeptides. Fluorescent images were obtained using a Zeiss fluorescent microscope and a Leica TSC confocal microscope equipped with an argon-krypton laser.

\section{RESULTS}

We grouped V2Rs according to their sequence conservation and immunized rabbits with expressed extracellular domains of representative V2R genes that encode members of distinct subfamilies. Antibodies against the N-terminal extracellular domain of three V2R-family receptors: Go-VN2, Go-VN3, and Go-VN4 labeled small subsets of VNO neurons (Fig. 1). For all the V2R antibodies, strongest immunoreactivity was in the cell body of VNO neurons, and as indicated in Figure $1 d$, expression of receptors was detectable in the sensory dendrites extending to the surface of the epithelium. In contrast, no specific immunostaining was observed in the axon bundles and accessory olfactory bulb of either adult or neonatal animals (data not shown).

The pattern of immunoreactivity observed with an antibody to V2R2 was markedly distinct. Unlike the punctate pattern of expression observed for the other V2Rs that we examined, the antibody to V2R2 labeled all neurons in the basal half of the sensory cell layer of the VNO (Fig. $2 a, b$ ). The cellular distribution of V2R2 was very similar to that of other V2Rs with prominent labeling of soma (Fig. 2a,b) and sensory microvilli (Fig. 2c) but no labeling of the axon bundles or accessory bulb (data not shown; Fig. 2d). To rule out the possibility that this antibody recognized a truncated receptor or other proteins expressed in a 

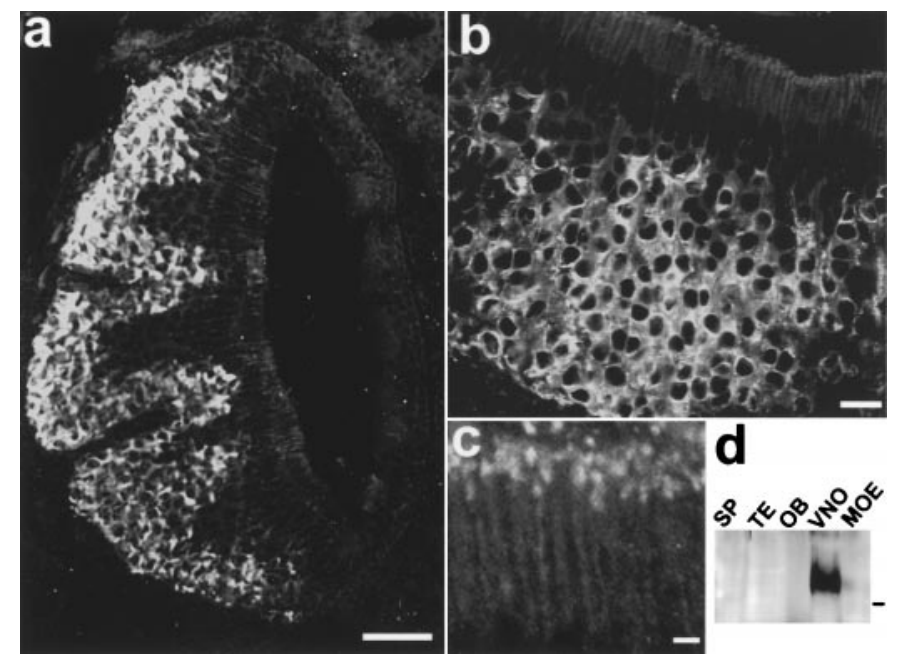

Figure 2. V2R2 is expressed in the cell bodies and sensory dendrites of a large subset of VNO neurons. Anti-mouse V2R2 stained all neurons in the basal half of the VNO epithelium in mouse $(a)$ and rat $(b)$; $c$, higher magnification of the luminal region of $b$ showing staining of dendrites and knobs. Scale bars: $a, 100 \mu \mathrm{m} ; b, 30 \mu \mathrm{m} ; c, 4 \mu \mathrm{m}$. $d$, Western blot of rat membrane protein extracts stained for anti-V2R2 immunoreactivity shows that this antibody recognizes an $\sim 100 \mathrm{kDa}$ protein that is expressed in the VNO, but not MOE, olfactory bulb (OB), spleen (SP), or testis (TE); the position of the $94 \mathrm{kDa}$ marker is indicated. a

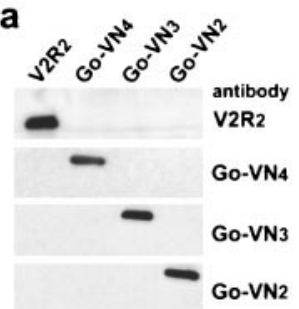

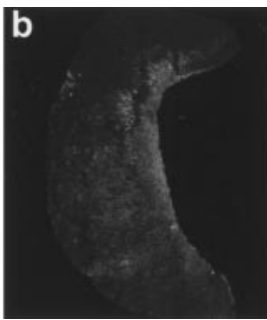

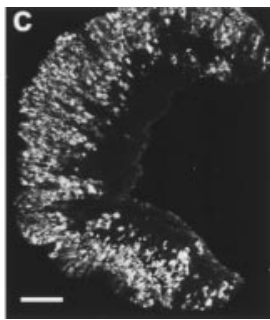

Figure 3. Specificity of antibodies to V2Rs. $a$, Western analysis of the four V2R-family antigens using the four antibodies; each antibody only recognizes the polypeptide against which it was raised. $b$, $c$, To demonstrate specificity of immunohistochemistry, the anti-V2R2 antibody was incubated with the polypeptide against which it was raised $(b)$ or a mix of three polypeptides encoding the same region of Go-VN2, Go-VN3, and Go-VN4 (c). Preincubation with the V2R2 antigen abolished immunostaining $(b)$, although preincubation with the other polypeptides had no effect on the pattern of immunohistochemistry (c). Scale bar, $100 \mu \mathrm{m}$.

large subset of neurons, we performed Western analysis. As expected, a single specific band was detected in the VNO membranes at $\sim 100 \mathrm{kDa}$, the size predicted for the V2R2 protein (Fig. $2 d$ ). No V2R2 immunoreactivity was detected in membranes from the olfactory bulb, confirming the results of immunohistochemistry or in membranes from a number of other tissues (Fig. $2 d$ ). This does not rule out the possibility that the V2R2 antibody recognizes other V2Rs. Therefore, the specificity of the antibodies was examined using Western blots of the fusion proteins against which they were raised. No cross- reactivity was detected (Fig. 3a). Moreover, preincubation of the V2R2 antibody with the polypeptide against which it was raised completely blocked immunodetection (Fig. 3b). In contrast, preabsorption of the antiV2R2 antibody with a mix of fusion proteins to other V2Rs resulted in no difference in the pattern or intensity of immunofluorescence (Fig. 3c). Preabsorption of other V2R antibodies with the fusion protein against which they were raised also abolished staining. However, incubation of these antibodies with
Table 1. Specificity of antibodies

Mean \pm SD number of cells detected per section

\begin{tabular}{lccc}
\cline { 2 - 4 } Antibody used & $\begin{array}{l}\text { Antibody } \\
\text { alone }\end{array}$ & $\begin{array}{l}\text { + V2R2-fusion } \\
\text { protein }\end{array}$ & $\begin{array}{c}+ \text { Immunogenic } \\
\text { fusion protein }\end{array}$ \\
\hline Anti-Go-VN2 & $72 \pm 7$ & $68 \pm 9$ & None detected \\
Anti-Go-VN3 & $57 \pm 4$ & $60 \pm 6$ & None detected \\
Anti-Go-VN4 & $129 \pm 9$ & $129 \pm 12$ & None detected
\end{tabular}

$\overline{\text { Staining cells in eight sections were counted for antibody alone and antibody }+}$ V2R2-fusion protein; adjacent serial sections were used for these incubations. Five sections were examined using each antibody incubated with the fusion protein against which it was raised.

the V2R2-fusion protein had no effect on the pattern or number of reactive cells (Table 1 ).

We also compared the high-stringency in situ hybridization pattern of the coding sequence of a rat V2R2 with the expression pattern detected with the antibody (Figs. 2b, 4a). Very similar distributions of mRNA and antibody staining were observed. We then used Southern analysis to examine whether there are a large number of receptors closely related to V2R2. The presence of several hybridizing bands in genomic digests probed at high stringency with a single exon probe to V2R2 (Fig. 5a) shows that there is a small subfamily of V2R2-related receptors. Screening of a rat $\mathrm{VNO}$ cDNA-library identified several receptors that are related in sequence to V2R2. Although these cDNAs were truncated at the $5^{\prime}$-end, preventing analysis of the full coding sequence, they were very closely related to V2R2 $(>85 \%$ sequence identity within the available coding sequence).

The divergent 3 '-nontranslated regions of three of these receptors were used to examine the expression pattern of individual V2R2 subfamily members in the VNO. The hybridization pattern of all three probes was essentially indistinguishable from that seen with a coding sequence V2R2 probe (Fig. 4). The 3'nontranslated region probes do not cross- hybridize at the stringency used for in situ hybridization. Indeed genomic Southern analysis indicates that these probes detect different genes, because the sizes of the hybridizing restriction fragments differ (Fig. $5 b$ ). Moreover, because two of these probes detect only single bands in genomic Southerns, it seems likely that several distinct but closely related V2R2 subfamily genes are expressed in a large subset of VNO sensory neurons. As expected for probes capable of detecting multiple mRNAs expressed within a single cell, coding sequence probes produced stronger signal (Fig. 4). These data clearly demonstrate that multiple V2R2-related transcripts are expressed in these cells and perhaps contribute to the immunostaining. However, to date, only a single full-length cDNA has been isolated for a V2R2 subfamily member. Therefore we cannot rule out the possibility that these neurons express multiple V2R2 pseudogenes together with a single V2R2 receptor protein.

To unambiguously demonstrate co-expression of V2R receptors, we performed double-label immunohistochemistry experiments and analyzed 1- $\mu$ m-thick optical sections using confocal microscopy. As expected, almost all the neurons expressing the V2R family receptors: Go-VN2, Go-VN3, and Go-VN4, also contained V2R2 (Fig. 6). This was observed along the entire length of the VNO and also was found for the apically located neurons that expressed Go-VN2 in male rats. We confirmed these results using in situ hybridization double labeling (Fig. 6). Therefore our results strongly suggest that many $\mathrm{G} \alpha_{\mathrm{o}}$-positive neurons express more than one V2R receptor. 
Figure 4. Several V2R2 subfamily members are co-expressed in the same VNO neurons. In situ hybridizations with digoxigenin-labeled RNA probes to rat V2R2 subfamily members label most neurons in the basal half of the sensory epithelium of rat VNO. Similar patterns of labeling were observed for a coding sequence probe to rat V2R2a $(a)$ and $3^{\prime}$ untranslated regions of rat V2R2a $(b)$, rat $\mathrm{V} 2 \mathrm{R} 2(c)$, and rat $\mathrm{V} 2 \mathrm{R} 2 \mathrm{~b}(d)$. The development time of staining was $12 \mathrm{hr}$ (a) and $60 \mathrm{hr}(b-d)$.
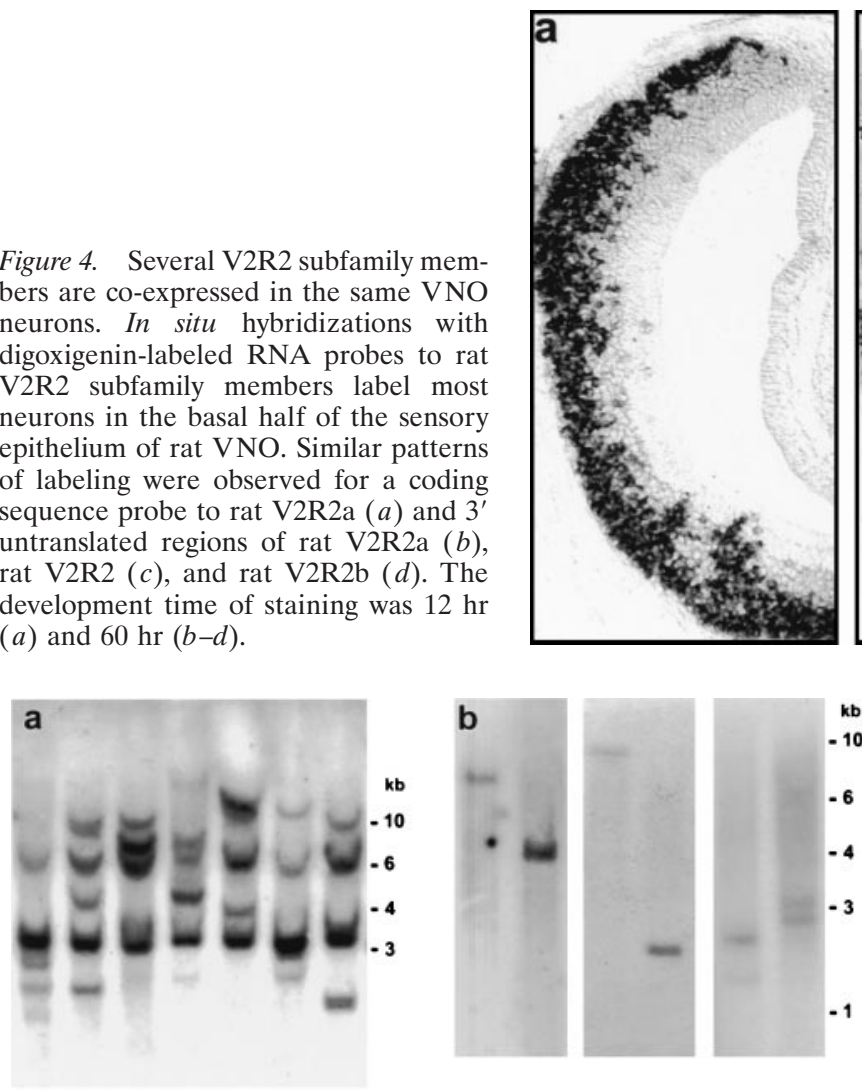

c

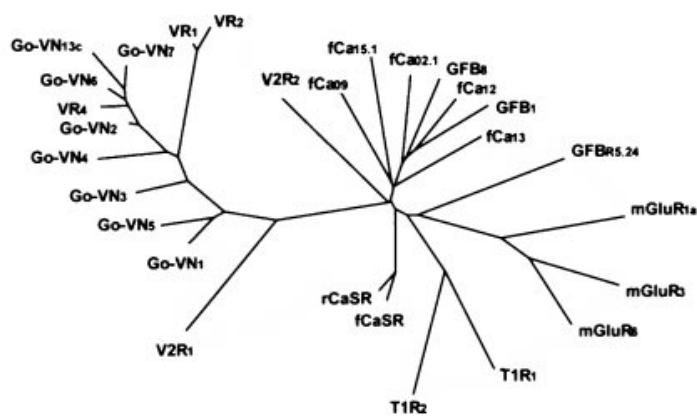

Figure 5. The V2R2 subfamily and its homology. $a$, Southern blot analysis of rat genomic DNA cut with EcoRI, BglII, PstI, BamHI, SacI, PvuII, and $X b a \mathrm{I}$ and screened at high stringency using a single extracellular exon probe to mouse V2R2 indicates the existence of a family of closely related genes. $b$, Southern blot analysis of rat genomic DNA cut with EcoRI or PstI and screened at high stringency with PCR products corresponding to the $3^{\prime}$-noncoding region of rat receptors V2R2, V2R2a, and V2R2b indicates that these probes recognize different genes of the V2R2 subfamily. $c$, The extracellular regions of the full-length rat and mouse V2Rs (V2R, Go-VN, and VR) and related fish-receptors (Ca, GFB, and R) were aligned with ClustalW, and the results were analyzed with Prot-dist and are shown as a neighbor-joining tree. The length of the joining roots indicates the divergence between receptors. Pairwise comparisons between the extracellular domains of V2R2 and other V2Rs yielded values of $\sim 25 \%$ identity; for other V2Rs identity ranged from $\sim 30 \%$ identity e.g., for $\mathrm{V} 2 \mathrm{R} 1$ and Go-VN2 to $\sim 50 \%$ identity e.g., for Go-VN2 and Go-VN4.

\section{DISCUSSION}

\section{V2R expression in VNO sensory neurons}

Recently it was shown that members of large family of putative pheromone receptors (V2Rs) are expressed in distinct subsets of VNO sensory neurons (Herrada and Dulac, 1997; Matsunami
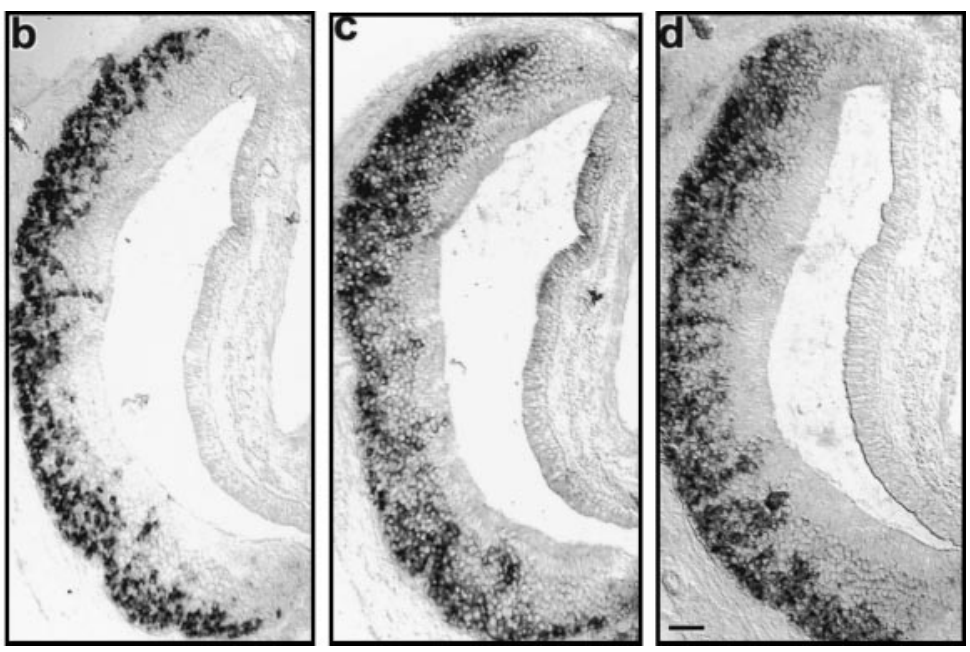

and Buck, 1997; Ryba and Tirindelli, 1997). However, the sequence of several V2R cDNAs indicated that many of these putative receptors might be expressed pseudogenes (Herrada and Dulac, 1997; Matsunami and Buck, 1997). Moreover, in the absence of functional data, other roles for these proteins (for example in directing axon projection) must also be considered (Belluscio et al., 1999; Rodriguez et al., 1999). Therefore we raised antibodies to investigate whether V2Rs are expressed proteins and to examine their distribution in VNO neurons.

The expression pattern of the $\mathrm{V} 2 \mathrm{R}$ proteins revealed by the antibody staining was remarkably similar to that obtained by in situ hybridization experiments (data not shown; Herrada and Dulac, 1997). For instance, anti-Go-VN3 antibodies labeled neurons localized to the basal layer of the $\mathrm{G} \alpha_{\mathrm{o}}$-positive zone, whereas anti-VN2 antibodies labeled cells extending to the apical region of the VNO. The number of neurons stained by the anti- $\mathrm{G}_{\mathrm{o}}-\mathrm{VN} 4$ antibodies was approximately three times greater than those identified by in situ hybridization with a corresponding cRNA probe, suggesting that this antibody may recognize an epitope found in more than one V2R. However, control experiments using high concentrations of the expressed $\mathrm{N}$-terminal domains of four representative V2Rs showed that the antibodies are specific within this group only recognizing the protein against which they were raised (Fig. 3).

Expression of receptors was detected in the sensory dendrites extending to the surface of the epithelium, consistent with a role for V2Rs as pheromone receptors (Figs. 1, 2). Nonetheless, the high degree of cellular staining is surprising for sensory receptors that might be expected to be concentrated at the luminal surface of the VNO. One possibility is that this distribution might reflect the fast turnover of the receptors exposed to the lumen of the VNO. A second potential role of the V2Rs might be in directing axon guidance (for example, see Belluscio et al., 1999; Rodriguez et al., 1999). However, the lack of immunoreactivity in the olfactory bulb (Fig. $2 d$ ), while not ruling out a role of these receptors in axon guidance mechanisms, suggests any role of V2Rs in axon guidance may be indirect.

\section{V2R2s are co-expressed with other V2Rs}

Both immunohistochemistry and in situ hybridization show that the expression pattern of V2R2 and closely related subfamily members is remarkably different from that of other V2Rs. In earlier studies (Ryba and Tirindelli, 1997), we mistakenly overlooked this difference because the weak signal obtained using 

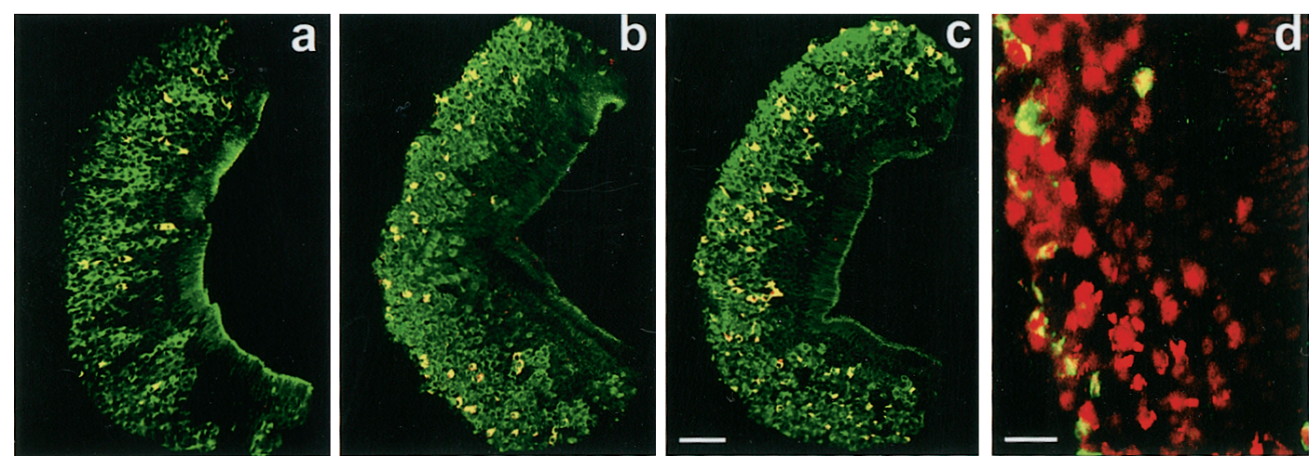

Figure 6. Co-expression of V2Rs in neurons of the VNO epithelium. Doublelabel immunohistochemistry and in situ hybridization directly demonstrates coexpression of V2Rs in rat VNO neurons. $a-c$, Images show double labeling with anti-V2R2 ( green) and anti-Go-VN2 (a), anti-Go-VN3 $(b)$, and anti-Go-VN4 (c) (red). Scale bar, $100 \mu \mathrm{m}$. Higher magnification image (Scale bar, $50 \mu \mathrm{m}$ ) of double label in situ hybridization $(d)$ of V2R2 (red) and rat Go-VN3 ( green) also shows co-expression.

3 '-nontranslated region probes to V2R2 requires significantly longer development times than the signal generated by other V2R probes. Thus, after short development times, only a few weakly staining scattered cells were detected (Ryba and Tirindelli, 1997). This weak staining suggests that cellular expression of any single V2R2 subfamily member is significantly lower than that of other V2Rs. However, in contrast to the small subsets of neurons that express most V2Rs, all neurons in the basal half of the sensory cell layer of the VNO appear to express several transcripts from the V2R2 subfamily (Figs. 2, 4, 5). Moreover, double-labeling experiments clearly demonstrate co-expression of several different V2Rs in V2R2 containing sensory neurons (Fig. 6).

These differences in expression raise the possibility that V2R2 plays a distinct role from other V2Rs. Sequence comparison of V2Rs also demonstrates that V2R2 is a divergent member of this family (Fig. 5) and places V2R2 closer to fish olfactory receptors than to other V2Rs. This may suggest closer functional similarity between V2R2 and these fish receptors, but equally may reflect the fact that only a small subset of V2R genes has been sequenced. The expression of V2R2 is restricted to the VNO and specifically to the $\mathrm{G} \alpha_{\mathrm{o}}$-expressing cells within this neurosensory epithelium (Herrada and Dulac, 1997; Matsunami and Buck, 1997; Ryba and Tirindelli, 1997). Moreover, the cellular distribution of immunoreactivity is very similar to that seen with antibodies to other V2Rs (Figs. 1, 2). Finally, as is the case for the other V2Rs, only a V2R2 pseudogene is found in the human high-throughput genomic sequences database. Therefore it appears that like the other V2Rs, V2R2 is a chemosensory receptor that probably plays a role in mediating pheromone responses.

The V2R-related family of receptors from fish olfactory epithelia also contains receptors that are expressed in a small subset of neurons and others that are more broadly expressed (Cao et al., 1998; Naito et al., 1998; Speca et al., 1999). Specifically, it has been shown that two goldfish receptors, 5.24 and 5.3, are expressed in a large subset of olfactory neurons. Thus here too, it is likely that receptors of this family are co-expressed in the same cells. Again it is notable that receptors 5.24 and 5.3 have the most divergent sequences (Speca et al., 1999; Fig. 5). Receptor 5.24 has been shown to respond to arginine and lysine, which are important odorant cues for fish. However, receptor 5.24 is only distantly related to V2R2, and therefore it is unlikely that V2R2 responds with similar ligand specificity.

What might be the functional significance of expressing multiple receptors in a single neuron? In the MOE, neurons express a single receptor, and neurons expressing a common receptor project to the same set of glomeruli (for review, see Mombaerts et al., 1996). Interestingly, olfactory receptors can detect more than one odorant, and odorants can be recognized by several receptors
(Malnic et al., 1999). Thus, mammals use combinatorial codes of glomeruli activation to discriminate odors (Rubin and Katz, 1999). The apical neurons of the rodent VNO are also thought to express only a single sensory receptor, however neurons expressing single V1Rs target multiple glomeruli (Belluscio et al., 1999; Rodriguez et al., 1999). Moreover, glomeruli appear to receive input from neurons expressing distinct V1Rs (Belluscio et al., 1999). This slightly different organization may facilitate stereotyped responses to specific mixes of odorants. Caenorhabditis elegans has a much simpler nervous system and uses a very different strategy that permits detection of many odorants but more limited discrimination between them. To do this, C. elegans chemosensory neurons express many receptors per cell (Troemel et al., 1995). Interestingly, the uniform bitter taste of many toxins also appears to result from the co-expression of several distantly related receptors in mammalian taste receptor cells (Adler et al., 2000; Chandrashekar et al., 2000). The co-expression of V2R2 with another $\mathrm{V} 2 \mathrm{R}$ receptor suggests that yet another mode of chemosensory information processing may occur. For example it is possible that ligands for V2R2 significantly alter the effects mediated by ligands to other V2Rs, either by sensitizing or desensitizing the cells. It is even conceivable that ligands for V2R2 might over-ride signals mediated by other V2Rs. However, a recent study of the effects of urine on VNO neurons provided no evidence for such an extreme model (Holy et al., 2000). An alternative hypothesis is that V2R2 might form heterodimers with other V2Rs. For example it has been shown that GABA-b receptors are composed of two distinct but related G-proteincoupled receptors (Jones et al., 1998; Kaupmann et al., 1998; White et al., 1998). In Drosophila the pattern of receptor expression most closely parallels the V2R receptor expression profile. Sensory neurons each express a single member of a family of $\sim 50$ odorant receptors (Vosshall et al., 2000), and in addition all express a highly divergent member of this gene family.

In conclusion, our data suggest that V2R2 and the other V2Rs have similar cellular localization and are present in the sensory region of the neurons, as would be expected for receptors involved in pheromone detection. However, the expression pattern of V2Rs is significantly more complex than for other vertebrate olfactory receptors. It will be fascinating to determine how these patterns of expression are regulated and to determine their role in chemosensory signaling and pheromone responses.

\section{REFERENCES}

Adler E, Hoon MA, Mueller KL, Chandrashekar J, Ryba NJP, Zuker CS (2000) A novel family of mammalian taste receptors. Cell 100:693-702.

Belluscio L, Koentges G, Axel R, Dulac C (1999) A map of pheromone receptor activation in the mammalian brain. Cell 97:209-220.

Berghard A, Buck LB (1996) Sensory transduction in vomeronasal neu- 
rons: evidence for $\mathrm{G}$ alpha o, $\mathrm{G}$ alpha i2, and adenylyl cyclase II as major components of a pheromone signaling cascade. J Neurosci 16:909-918.

Berghard A, Buck LB, Liman ER (1996) Evidence for distinct signaling mechanisms in two mammalian olfactory sense organs. Proc Natl Acad Sci USA 93:2365-2369.

Brown EM, Gamba G, Riccardi D, Lombardi M, Butters R, Kifor O, Sun A, Hediger MA, Lytton J, Hebert SC (1993) Cloning and characterization of an extracellular $\mathrm{Ca}\left({ }^{2+}\right)$-sensing receptor from bovine parathyroid. Nature 366:575-580.

Cao Y, Oh BC, Stryer L (1998) Cloning and localization of two multigene receptor families in goldfish olfactory epithelium. Proc Natl Acad Sci USA 95:11987-11992.

Chandrashekar J, Mueller KL, Hoon MA, Adler E, Feng L, Guo W, Zuker CS, Ryba NJP (2000) T2Rs function as bitter taste receptors. Cell 100:703-711.

Dulac C, Axel R (1995) A novel family of genes encoding putative pheromone receptors in mammals. Cell 83:195-206.

Halpern M (1987) The organization and function of the vomeronasal system. Annu Rev Neurosci 10:325-362.

Halpern M, Shapiro LS, Jia C (1995) Differential localization of G proteins in the opossum vomeronasal system. Brain Res 677:157-161.

Harlow E, Lane D (1988) Antibodies: a laboratory manual. Cold Spring Harbor, New York: Cold Spring Harbor.

Herrada G, Dulac C (1997) A novel family of putative pheromone receptors in mammals with a topographically organized and sexually dimorphic distribution. Cell 90:763-773.

Holy TE, Dulac C, Meister M (2000) Responses of vomeronasal neurons to natural stimuli. Science 289:1569-1572.

Hoon MA, Adler E, Lindemeier J, Battey JF, Ryba NJP, Zuker CS (1999) Putative mammalian taste receptors: a class of taste-specific GPCRs with distinct topographic selectivity. Cell 96:541-551.

Jia C, Halpern M (1996) Subclasses of vomeronasal receptor neurons: differential expression of $\mathrm{G}$ proteins ( $\mathrm{Gi}$ alpha 2 and $\mathrm{G}(\mathrm{o}$ alpha)) and segregated projections to the accessory olfactory bulb. Brain Res 719:117-128.

Jones KA, Borowsky B, Tamm JA, Craig DA, Durkin MM, Dai M, Yao WJ, Johnson M, Gunwaldsen C, Huang LY, Tang C, Shen Q, Salon JA, Morse K, Laz T, Smith KE, Nagarathnam D, Noble SA, Branchek TA, Gerald C (1998) GABA(B) receptors function as a heteromeric assembly of the subunits GABA(B)R1 and GABA(B)R2. Nature 396:674-679.

Kaupmann K, Malitschek B, Schuler V, Heid J, Froestl W, Beck P, Mosbacher J, Bischoff S, Kulik A, Shigemoto R, Karschin A, Bettler B (1998) GABA(B)-receptor subtypes assemble into functional heteromeric complexes. Nature 396:683-687.

Keverne EB (1983) Pheromonal influences on the endocrine regulation of reproduction. Trends Neurosci 6:381-384.

Leinders-Zufall T, Lane AP, Puche AC, Ma W, Novotny MV, Shipley
MT, Zufall F (2000) Ultrasensitive pheromone detection by mammalian vomeronasal neurons. Nature 405:792-796.

Malnic B, Hirono J, Sato T, Buck LB (1999) Combinatorial receptor codes for odors. Cell 96:713-723.

Matsunami H, Buck LB (1997) A multigene family encoding a diverse array of putative pheromone receptors in mammals. Cell 90:775-784.

Mombaerts P, Wang F, Dulac C, Vassar R, Chao SK, Nemes A, Mendelsohn M, Edmondson J, Axel R (1996) The molecular biology of olfactory perception. Cold Spring Harb Symp Quant Biol 61:135-145.

Naito T, Saito Y, Yamamoto J, Nozaki Y, Tomura K, Hazama M, Nakanishi S, Brenner S (1998) Putative pheromone receptors related to the $\mathrm{Ca}^{2+}$-sensing receptor in Fugu. Proc Natl Acad Sci USA 95:5178-5181.

Nakanishi S (1992) Molecular diversity of glutamate receptors and implications for brain function. Science 258:597-603.

Novotny M, Jemiolo B, Harvey S, Wiesler D, Marchlewska-Koj A (1986) Adrenal-mediated endogenous metabolites inhibit puberty in female mice. Science 231:722-725.

Rodriguez I, Feinstein P, Mombaerts P (1999) Variable patterns of axonal projections of sensory neurons in the mouse vomeronasal system. Cell 97:199-208.

Rubin BD, Katz LC (1999) Optical imaging of odorant representations in the mammalian olfactory bulb. Neuron 23:499-511.

Ryba NJP, Tirindelli R (1997) A new multigene family of putative pheromone receptors. Neuron 19:371-379.

Speca DJ, Lin DM, Sorensen PW, Isacoff EY, Ngai J, Dittman AH (1999) Functional identification of a goldfish odorant receptor. Neuron 23:487-498.

Takigami S, Osada T, Yoshida-Matsuoka J, Matsuoka M, Mori Y, Ichikawa M (1999) The expressed localization of rat putative pheromone receptors. Neurosci Lett 272:115-118.

Tirindelli R, Ryba NJP (1996) The G-protein gamma-subunit G gamma 8 is expressed in the developing axons of olfactory and vomeronasal neurons. Eur J Neurosci 8:2388-2398.

Tirindelli R, Mucignat-Caretta C, Ryba NJP (1998) Molecular aspects of pheromonal communication via the vomeronasal organ of mammals. Trends Neurosci 21:482-486.

Troemel ER, Chou JH, Dwyer ND, Colbert HA, Bargmann CI (1995) Divergent seven transmembrane receptors are candidate chemosensory receptors in C. elegans. Cell 83:207-218.

Vosshall LB, Wong AM, Axel R (2000) An olfactory sensory map in the fly brain. Cell 102:147-159.

White JH, Wise A, Main MJ, Green A, Fraser NJ, Disney GH, Barnes AA, Emson P, Foord SM, Marshall FH (1998) Heterodimerization is required for the formation of a functional GABA(B) receptor. Nature 396:679-682.

Wu Y, Tirindelli R, Ryba NJP (1996) Evidence for different chemosensory signal transduction pathways in olfactory and vomeronasal neurons. Biochem Biophys Res Commun 220:900-904. 